\title{
The association between nutrient intake, nutritional status and physical function of community-dwelling ethnically diverse older adults: A longitudinal study
}

Evans Atiah Asamane ( $\nabla$ asamaneevans@yahoo.com )

University of Birmingham School of Sport Exercise and Rehabilitation Sciences https://orcid.org/0000-0002-6430-7787

Carolyn A. Greig

University of Birmingham School of Sport Exercise and Rehabilitation Sciences

Janice Lee Thompson

University of Birmingham School of Sport Exercise and Rehabilitation Sciences

\section{Research article}

Keywords: Nutrient intake, physical function, nutritional status, ageing, ethnic minority, older adults, United Kingdom.

Posted Date: October 23rd, 2019

DOI: https://doi.org/10.21203/rs.2.16366/v1

License: @ (i) This work is licensed under a Creative Commons Attribution 4.0 International License. Read Full License

Version of Record: A version of this preprint was published on August 25th, 2020. See the published version at https://doi.org/10.1186/s40795-020-00363-6. 


\section{Abstract}

Background There are limited longitudinal data regarding nutrient intake, nutritional status and physical function in community-dwelling ethnically diverse older adults. This study explored these variables and their relationship at baseline $(n=100)$ and 8-months' follow-up ( $n=81)$ among community-dwelling ethnically diverse older adults ( $\geq 60$ years) in Birmingham, United Kingdom.Methods Multiple-pass 24-hour dietary recalls and the Mini Nutritional Assessment-Short Form assessed nutritional intake and status, respectively. Short Physical Performance Battery (SPPB) and handgrip strength measured physical function. Linear and multinomial regressions were used to predict relationships between physical function, nutritional status and nutrient intake.Results Participants at baseline $(n=100)$ and 8-months' follow-up ( $n=81)$. Mean (SD) age was 70 (8.1) years (60\% male), with 62\% being obese. Decreases in intakes of vitamin B6, vitamin B1, iron, folate, and magnesium occurred over time. Daily intake of all micronutrients except vitamin B12, phosphorus and manganese were below the Recommended Nutrient Intakes (RNI). SPPB $(Z=-4.01, p<0.001)$ and nutritional status $(Z=-2.37, p=0.018)$ declined over time. Higher SPPB scores $(\mathrm{OR}=0.5495 \% \mathrm{Cl} 0.35,0.81)$ were associated with a slower decline in nutritional status. Conclusion The observed declines and inadequate nutrient intakes in the absence of weight loss in just eight months may pose serious challenges to healthy ageing, identifying an urgent need to reevaluate and tailor appropriate dietary advice for this population.

\section{Background}

The world population is increasing and ageing rapidly, with developed countries having the highest proportion of ageing populations compared to developing countries[1]. In the United Kingdom (UK), there was a total of 11.2 million people aged 65+ years, representing $18 \%$ of the population in 2016 [2]. It is projected that by 2030 , one in five people will be aged $65+$ years, comprising $21.8 \%$ of the population [3]. Furthermore, the UK population is becoming increasingly ethnically diverse, with ethnic minorities significantly ageing alongside the white population[4]. According to the findings from the 2011 Office for National Statistics (ONS), it is projected that by 2051, there will be 3.8 million BME people aged 65+ years and 2.8 million BME aged 70+ years [4]. The ageing and increasing ethnic diversity of the UK population has implications not only to the quality of life of the individual but significantly impacts on health and social care systems, the economy and the lives of family members $[2,5,6]$.

Furthermore, many BMEs are often faced with lower socio-economic status and disproportionate health inequalities, which accounts for the differences in health outcomes among ethnic minorities and the white European population [7-9]. For instance, as evident in the findings of the Health Survey England (HSE), the prevalence of obesity among Black African women is $38 \%$ (risk ratio 2.0 ), and $32.1 \%$ among Black Caribbean women (risk ratio 1.43 ) compared to $23 \%$ in the general white British population of women [10]. While recognising these differences in health outcomes, dietary habits of BMEs have been shown to become unhealthy mainly due to financial constraints, language barriers, age, availability of traditional foods, and years spent in the host country [11-13]. A study in the UK found that older BME women with a mean age of 70.5 years had inadequate intakes of vitamin $\mathrm{D}$, selenium, magnesium and potassium, and attributed reasons such as age, reduced physical activity and dietary restrictions to be influencing dietary intake [11]. Considering the ultimate role of diet as a modifiable factor in obesity and related chronic diseases, and the limited literature regarding it, it is essential to study the trends in nutrient intake particularly in this population with a relatively high prevalence of obesity and diet-related chronic diseases [10]. Most studies exploring nutrient intakes in ethnic minorities have focused only on south Asian population, single ethnic groups, or mainly one sex limiting a clearer understanding of the differences shared within and between ethnic minorities $[11,14,15]$. The present study is an initial step towards increasing knowledge on the heterogeneity and gender differences in nutrient intakes over time among ethnic minority older adults living in the super-diverse communities.

Besides nutrition, the promotion and maintenance of good physical function are crucial in improving quality of life, nutrient intake and reducing institutionalisation, hospitalisation and mortality among older adults [16-18]. Ethnic minority groups and older adults living in lower socio-economic environments often have a lower physical function as compared to the general population [19, 20]. Despite this, few studies have explored the risk factors, specifically the impact of nutrient intake and nutritional status on the maintenance of physical function in this population. Published findings from non-ethnic minority community-dwelling older adults have shown that good nutrition can improve and maintain higher physical function such as keeping up with activities of daily living and preventing falls [21,22]. For instance, a study of 689 community-dwelling older adults with a mean age of 75.7 years, found that an increased dietary diversity was closely associated with better scores activities of daily living, lower depression scores and increased quality of life [21]. Considering these and the relatively higher risk of physical function limitations within this population, it has become more pertinent to explore the profile of nutrition and physical function, and their association over time among community-dwelling, ethnically diverse older adults.

The few studies that have examined these variables within this population are usually cross-sectional, with many employing a subjective measure of physical function and providing limited information on dietary intake and nutritional status. Additionally, the cross-sectional nature of these studies also hinders a deeper understanding of the impact of the time element on the relationships between diet, nutritional status, and objectively measured physical function. The present study aimed to: 1) provide a clearer understanding of the profile of nutrient intake, nutritional status and objectively measured physical function over time; and 2) explore how nutrient intake and nutritional status are associated with physical function over time in this population.

\section{Methods}

\subsection{Study Design and Setting}

An observational longitudinal quantitative approach was used to examine nutrition and physical function over eight months. The study was conducted in the Birmingham area, West Midlands, UK. In this geographical location, ethnic minorities (non-white) comprise $46.9 \%$ of the population, with the largest group being South Asians (comprising $22.5 \%$ of the total population), and it is projected that ethnic minorities will become the majority of the population by 2021 $[23,24]$. 
The sample included community-dwelling, ethnically diverse older adults aged 60 years and older, and self-identifying as Pakistani, Indian, Bangladeshi, Caribbean and/or African. In addition to these, other inclusion criteria encompassed residing in the Birmingham area, non-institutionalised and with no known diagnosis of dementia or any mental illness that will impair participation. A convenience sample of 100 participants were recruited through community centres, age-well societies, faith/religious centres and other informal social events by word of mouth. The rationale was to recruit a more representative sample, thus maximum variation technique was introduced after recruiting 60 participants [25].

\subsection{Measures}

There were four different contact points for data collection, two completed within 14 days at baseline and repeated in the same format after eight months of follow-up. Socio-demographic data including date of birth, sex, marital status, educational status, faith, ethnicity, and years residing in the UK were collected using a bespoke questionnaire, at baseline and at follow-up. The Index of Multiple Deprivation (IMD) was computed as an indicator of deprivation using the participant's postcode [26]. Weight was measured to the nearest $0.1 \mathrm{~kg}$ and height to the nearest $0.1 \mathrm{~cm}$, using a Seca 899 digital scale and Seca 213 portable stadiometer, respectively. Body Mass Index (BMI) was calculated using the standard equation; weight $(\mathrm{kg}) / \mathrm{height}^{2}\left(\mathrm{~m}^{2}\right)$. Waist circumference $(\mathrm{WC})$ was measured and recorded to the nearest $0.01 \mathrm{~cm}$ using a flexible retractable non-elastic tape.

\subsubsection{Dietary assessment}

Dietary intake was assessed using the multiple-pass 24-hour recall, following standard procedures [27]. EAA, a trained nutritionist with relevant expertise in conducting dietary assessments, conducted all assessments with regular data checks from JLT, a Professor of Public Health Nutrition and Exercise, with extensive experience in dietary assessments in diverse populations. A culturally-appropriate food portion booklet containing ethnic minority foods, accompanied by standard household food measures, were used to estimate portion sizes [28]. In total, four 24-hour recalls were collected, two nonconsecutive days each at baseline and follow-up. In instances where participants had fasted within the previous 24 hours, the record was discarded, and a new day assigned to retake the record $(n=17)$. All 24-hour recall interviews were digitally recorded to enhance the quality of the data during data entry. Detailed recipes were gathered for home-cooked meals, and brand names and cooking methods were recorded during interviews. In addition, nutrient supplement usage was collected during dietary assessments. After each visit, the multiple-pass 24-hour recall data were checked for accuracy using the interviews before entering these data for processing into a dietary software analysis package, Dietplan 7.0 (Forestfield Software Ltd, Horsham, West Sussex, UK). Dietplan 7 was appropriate as it utilises UK-specific databases such as McCance and Widdowson, as well as relevant ethnic minority food databases. In instances that a food item could not be found in the software databases, these were added to the database using food manufacturing websites and other food composition tables. Nutrient data obtained from the analysis were compared with the age and sex-specific UK Dietary Reference Values (DRV) [29].

\subsubsection{Nutritional status}

Nutritional status was assessed using the Mini-Nutritional Assessment-Short Form (MNA-SF). This is a simple to use, sensitive, reliable, and valid tool for rapid assessment of nutritional status of older adults [30]. Unlike the full MNA, the short form is more rapid (can be completed within 10 minutes) and equally reliable to the full MNA [31,32]. Given the validity and quick administration, it was the preferred option to assess nutritional status as it reduces participant burden during data collection. Additionally, as this study was part of a larger study, MNA was the tool chosen to measure nutritional status [33]. The MNA-SF is composed of six major items and has a scoring of 0-14 points, with 0-7 classified as malnourished, 8-11 classified as at risk of malnutrition, and 12-14 classified as normal [32].

\subsubsection{Physical function}

The Short Physical Performance Battery (SPPB) was used to measure participants' lower body extremity function [17, 34]. SPPB has been widely validated to measure accurate physical function and serves as a prediction of mobility, disability and mortality in older adults [16]. SPPB includes a balance test conducted in side by side, semi-tandem, and tandem positions, as well as 4-metre walk test at one's self-selected 'natural' pace, and a test of their ability to rise five times from a chair as quickly as possible. The maximum score from these three components makes up a total score of 12 on the SPPB; a score of 0 indicates the worst performance, while a score of 12 indicates the best performance.

Handgrip Strength (HGS) was also used to measure physical function. HGS was measured in kilogram (Kg) using a Jamar hand dynamometer (Sammons Preston, Inc., Bolingbrook, IL) per the NHANES protocol for measuring HGS in the standing position, with arms by the side [35]. Handle width was adjusted to hand size, and each measurement performed three times [36]. The standing position was chosen as it has been shown to produce maximal grip strength as compared to the other positions in measuring HGS [37].

\subsection{Statistical Analysis}

Nutrient density was computed by dividing the nutrient intake by the total energy intake and multiplying it by 1000kcal/day [38]. Independent T-test and chisquare test were conducted to test for differences in continuous and categorical variables, respectively, at both time points. The Wilcoxon signed-rank test was used to test for median differences in instances where the continuous variables failed to meet the assumptions for a t-test. Prior to conducting the above analyses, normality was tested using the Shapiro-Wilk test and Q-Q plots. Marital status was later regrouped as married and not married, educational status was regrouped as educated and not educated, the number of diseases grouped as number of diseases $\leq 2$ and number of diseases $>2$, and ethnicities regrouped as South Asian (Pakistanis, Indians and Bangladeshis), African-Caribbean (Africans and Caribbean), and 'other ethnicity, (mixed ethnicities). Given the smaller numbers in each group, these regroupings were done to satisfy the assumptions needed to run some of the analyses.

For energy and macronutrient intakes, both mean (SD) and median (IQR) were presented. Micronutrient intakes and all other variables that satisfied normally distributed characteristics were presented as mean (SD), while those that were not normally distributed were presented as median (IQR). Categorical variables 
were presented as number $(\mathrm{N})$ and percentages. The percentage of nutrient intake of the RNI defined for that nutrient was computed to ascertain whether the participant met the recommendations [39]. One-way ANOVA and Kruskal Wallis were performed to examine any differences in nutrient intake by ethnicities and other socio-demographic characteristics.

A pairwise correlation was conducted, and the variables correlated with physical function $(p<0.05)$, were built into a hierarchical model to test the predictors of physical function (SPPB and HGS) while controlling for variables of interest. For longitudinal analysis regarding physical function, the difference in physical function between both time points was computed and classified into the following groups: improved, declined and stable. In logistic regression, the improved/stable and declined groups were used as outcome variables to test factors predicting changes in physical function at follow-up. Regarding nutritional status, the at-risk of malnutrition and the malnourished groups were combined to form malnourished/at-risk of malnutrition group, while the normal nutritional status group was maintained as originally defined. Changes in nutritional status were 1) those who remained in the malnourished/at-risk of malnutrition; 2) those who declined from the normal to the malnourished/at-risk of malnutrition group; 3) those who improved from malnourished/at-risk of malnutrition to the normal group; and 4) those who remained in the normal group. Multinomial regression was used to predict the membership of these four nutritional status groups. A sensitivity analysis was conducted to ascertain differences in nutrient intakes with or without supplement intakes at both time points. All statistical analyses were conducted using IBM SPSS version 25 (IBM Corp, Armonk, NY, 2012) with significance set at $p<0.05$.

\section{Results}

Socio-demographic and other health-related data for participants at baseline and after eight months of follow-up are presented in Table 1. Of the 19 of participants who did not complete the study, 5 did not continue due to sickness, 8 were no longer interested, and the remaining 6 could not be reached during follow-up. At baseline the mean (SD) age was 70.8 (8.1), with 59\% male. Most of the participants were married and had a University or college degree.

Older adults completing the study had a significantly higher SPPB $(P=0.007)$, HGS $(p=0.027)$ and lower WC $(p=0.036)$ as compared to those lost to follow-up $(n=19)$. All other variables of interest were not significantly different (See additional file 1$)$.

\section{[Insert table 1]}

3.1 Energy and Macronutrient Intakes Over Time Compared with DRVs

Mean (SD) and median (IQR) values for energy and nutrient intakes are reported in Table 2. Energy intakes for both sexes at both time points were below the estimated average requirement based on the population with low physical activity levels. There was a decrease in polyunsaturated fatty acids intake for females at follow-up ( $\mathrm{P}=0.04)$ (Table 2). The mean percentage Total Energy (\%TE) from carbohydrates at baseline and follow-up for both sexes were slightly above the DRV. However, the \%TE from fat at both time points for females were below the DRV $(31.3 \%$ and $32.3 \%$, respectively, vs $35 \%)$.

\section{[Insert table 2]}

There were also differences in nutrient intakes by ethnicity. As shown in table 3, South Asians reported significantly higher intakes of energy ( $p=0.003)$ and $\%$ TE PUFA $(p<0.001)$ at both time points. Additionally, South Asians reported significantly higher intakes of \%TE total fat at follow-up ( $p=0.048)$.

\subsection{Micronutrient Intakes Over Time Compared with RNIs}

There were significant median decreases for only the following micronutrients: vitamin B6, vitamin B1, iron, folate and magnesium. In total, 39\% (56\% Female) and $35 \%$ (54\% females) of participants reported taking micronutrient supplements during baseline and follow-up assessments, respectively. The most common supplements reported included multivitamins, vitamin C, vitamin D, iron and calcium. A sensitivity analyses revealed that for females at baseline, there were significant differences in intakes with and without supplementation in relation to vitamin $D$, vitamin $A$, vitamin $E$, thiamine, riboflavin, niacin, vitamin B6, vitamin B12, folate and vitamin C intakes (Additional file 2). For males, there were significant differences in the intakes of vitamin A, vitamin D, vitamin E, vitamin $\mathrm{C}$ and folate between intakes with supplementation and intakes without supplementation (Additional file 2). Micronutrient intakes with and without supplementation for females differed in vitamin A, vitamin D, vitamin B1, vitamin E vitamin B6, vitamin B12, vitamin C and manganese intakes at follow-up. However, there were no differences found for males (Additional file 3).

Compared to the UK RNI, total daily intake of most nutrients were below the recommendation. Expressed as a percentage of RNI (Figure 1), daily intakes of vitamin B12, phosphorus and manganese for both sexes, and vitamin A, vitamin E, vitamin C, thiamine and niacin for females met the RNI. At follow-up, the pattern was similar for both sexes; except for phosphorus, manganese, vitamin C and vitamin B12, all other micronutrients were below the RNI.

\section{[Insert figure 1]}

\subsection{Cross-sectional Associations}

Baseline pairwise correlation found that SPPB was significantly associated with WC ( $r=-0.466)$, MNA-SF $(r=0.391)$, BMI $(r=-0.224), \mathrm{HGS}(r=0.610)$, fibre $(r=0.265)$, vitamin B6 ( $r=0.303)$ and vitamin D ( $r=0.223)$. Nutritional status measured by MNA-SF was significantly associated with vitamin $D(r=0.237)$ and HGS ( $r=0.198)$ (Additional material 4).

Using the results from the pairwise correlation, hierarchical multiple regression was conducted to determine the contribution of each independent variable to physical function performance and nutritional status. Table 3 shows the fully adjusted model for sociodemographic variables, nutritional status, WC, BMI and 
nutrient intakes as predictors of the SPPB and HGS.

Given that only fibre, vitamin D and vitamin B6 were found to be correlated with SPPB and HGS, they were the only nutrients included in the multiple regression analyses. Higher SPPB scores were associated with being younger, married, a lower WC, and higher fibre and vitamin $D$ intakes $\left[R^{2}=0.534, F(12,87)=8.319\right.$, $\mathrm{p}<0.01]$. For HGS, increasing age was significantly associated with lower HGS scores. In addition, those living in the least deprived areas (determined by the IMD scores) and reporting higher fibre intakes had significantly higher HGS scores $\left[R^{2}=.0423, F=(12,87)=5.317, p<0.01\right]$.

A hierarchical multiple regression was conducted to test the association of nutritional (MNA-SF) and physical function while controlling for all confounders (see Table 5). This was to determine the impact of nutrient intake and physical function (SPPB and HGS) as predictors of nutritional status. SPPB was the only predictor of nutritional status, with no other variables being significantly associated with nutritional status $\left[R^{2}=.0278, F=(14,85)=2.334, p=0.009\right]$. After controlling for all confounders, higher SPPB scores were associated with better nutritional status.

\subsection{Longitudinal Associations}

There were significant changes in nutritional status measured using MNA-SF, and physical function using SPPB scores over time, $(Z=-2.37, p=0.018)$ and $(Z=-4.01, p<0.001)$ respectively (Table 1). Per the MNA-SF cut-offs, $24 \%$ were malnourished/at-risk of malnutrition, and the remaining ( $76 \%)$ were normal at baseline. At follow-up, 37\% were malnourished/at-risk of malnutrition, and remaining (63\%) were normal. In summary, the proportion of people reporting normal status reduced, while those reporting malnourished/at-risk of malnutrition increased by $13 \%$ at follow-up. The changes in nutritional status were: 1) those who remained malnourished/at-risk of malnutrition at follow-up (12.3\%); 2) those who changed to malnourished/at-risk of malnutrition at follow-up $(24.7 \%) ; 3)$ those who changed to normal at follow-up ( $n=8.6 \%)$; and 4$)$ those who remained normal at follow-up (54.3\%).

Using 'remained normal at follow-up' as the reference category in a multinomial regression (Table 6), the results indicate no significant predictors determining the likelihood of remaining malnourished/at-risk of malnutrition as compared to the reference group. However, participants with a higher SPPB score at baseline $(\mathrm{OR}=0.61)$ were less likely to change to being malnourished/at-risk of malnutrition. Conversely, participants with a higher $\mathrm{BMI}(\mathrm{OR}=1.29)$ or WC $(\mathrm{OR}=$ 1.10) were more likely to change to being malnourished/at-risk of malnutrition compared to the reference group.

Regarding SPPB at follow-up, 35.8\% remained stable, $47 \%$ had a lower score, and $17.2 \%$ improved their score. Computed into two groups, improved/stable and decline served as outcome variables in a logistic regression performed to determine the significant predictors of changes in SPPB at follow-up. The results indicate that with an increase in age $(O R=1.105, p=0.005)$ or increase in the number of diseases reported $(O R=1.63, P=0.033)$, participants were more likely to experience a decline in physical function than to improve or remain stable. All other variables showed no significant association with the changes in physical function (See details in additional file 4).

\section{Discussion}

This study provides unique and potentially useful evidence regarding the profile of nutrient intakes, nutritional status, and physical function, and their relationships over time, in a sample of ethnically diverse community-dwelling older adults. These findings are particularly relevant as they add to existing literature to broaden our understanding of the relationship between diet and components of healthy ageing within this population. Also, the findings are both timely and pertinent given the growing ethnic diversity in the UK and some parts of Europe, highlighting the need for culturally adapted interventions specifically around diet and physical function to support this group to age more healthfully $[4,40]$.

The intakes of energy and most nutrients remained unchanged, except decreases in the daily intakes of magnesium, folate, vitamin B1, vitamin B6 and iron. This finding concurs with a 10-year longitudinal study of 25 South Asian women (mean age of 54.2 years) in Glasgow [41]. This study used a 7-day weighed food dairy and found no significant difference in energy intake. However, the findings contrast sharply with the Melbourne Chinese Cohort Study, composed of 262 Chinese adults with a mean age $>50$ years [42]. The authors found that intakes of energy, fats, fibre and protein increased significantly over eight years among women, but not men. Among men, the only significant change was a decrease in carbohydrate intake. This study utilised FFQ, which has been found to overestimate nutrient intakes in older adults [27]. This, coupled with the failure of the authors to account for an increase in nutrient supplement intakes at follow-up, could partially account for the differences between these studies. Additionally, the relatively shorter duration of follow-up in the present study as compared to the Melbourne study could also contribute. Furthermore, as previously reported in this sample, eating patterns were linked to cultural and religious purposes rather than health reasons, which could account for the stability of energy and macronutrient intakes over time [43].

In the context of the broader literature, the energy intakes observed over time in this study were comparable with those of the energy intakes of predominately white older adults in the UK aged 65+ years as reported in the National Diet and Nutrition Survey (NDNS) [44]. Also, the energy intakes of males in the present study ( $1853.8 \mathrm{kcal} / \mathrm{day}$ baseline and $1822 \mathrm{kcal} /$ day follow-up) were comparable to energy intakes of males in the Newcastle $85+$ cohort (1848 kcal/day), but those of females (1358.5 kcal/day baseline and $1243.5 \mathrm{kcal} /$ day follow-up) were less than the female energy intake values reported in the Newcastle $85+$ cohort (1471 kcal/day) [45]. Additionally, the \%TE from carbohydrates, protein, MUFA, and PUFA in the present study were higher, while the \%TE from saturated fat was lower than the Newcastle 85+ cohort [45]. It has been observed that the traditional foods of ethnic minorities, with the exception of South Asian diets, are relatively higher in \%TE from carbohydrate and lower in \%TE from fats (including saturated fats), as compared to western diets [46, 47]. Hence, this difference in food composition between these ethnic groups and the disparity in age between the present sample and the Newcastle $85+$ cohort might be accounting for the differences in energy and macronutrient intakes observed. The relatively high total energy and \%TE from fats within the South Asian diets 
were also confirmed in this study, with participants identifying as South Asian having significantly higher intakes of total energy and \%TE from fats as compared to those identifying as being African-Caribbean.

Another key finding from the present study is the inadequate amounts of micronutrients consumed. The intakes of these nutrients below the RNI were consistent at follow-up, suggesting a potential micronutrient deficiency in this sample. Given the importance of micronutrients for maintenance of good health, physical function and better quality of life, the low intakes are of concern, particularly when one considers the relatively high prevalence of noncommunicable disease within this population [10]. The inadequate intake of various nutrients among older ethnic minorities in the present study is consistent with previous studies in the UK and elsewhere [11, 48]. However, in contrast to the present findings, the results from Years 7 and 8 (combined) of the UK NDNS Rolling Programme (a sample comprised of predominately white older adults), found that intakes of most micronutrients were at the RNI or above the RNI [44]. Variations in the level of deprivation between these two samples could be one factor accounting for these differences. It has been reported elsewhere that poverty and other forms of deprivation lead to poorer diets, and subsequently, a higher prevalence of malnutrition, in both community and hospital settings $[49,50]$. Recently, the English Longitudinal Study of Ageing reported that being non-white (OR: 3.8; 95\% Cl 2.39-6.05) and obese (OR: 1.32; 96\% Cl 1.09-1.58) were associated with a higher vitamin D deficiency [51]. These findings further highlight the inequalities in nutrient intakes and the need for increasingly culturally tailored community-focussed interventions to promote adequate nutritional intake and the general health of this population.

Given the critical role of supplementation and the increased tendency of poorer nutrition in later life, nutrient supplementation is beneficial to healthy ageing $[52,53]$. For instance, a meta-analysis of randomised controlled trials concluded that supplementation of $17.5-25 \mu \mathrm{g}$ of vitamin D daily reduces the risk of falls by $19 \%$ in older adults [53]. The vital role of nutrient supplementation observed in this study adds to the literature; supplementation significantly contributed to meeting the RNI for nutrients such as vitamin A, vitamin D, vitamin B6 and vitamin B12, thiamine, niacin and vitamin E. However, the consumption of supplementation was relatively low over time, and lower for males as compared to females. Further studies explicitly examining prolonged supplementation within this population is needed to confirm our findings. However, given the benefits of supplementation observed, this population might benefit considerably from micronutrient supplementation.

Nutritional status and physical function declined significantly over the study period. The findings showed an increase of $13 \%$ in the number of people classified as malnourished or at-risk of malnutrition over the study period. Likewise, over time, almost half (47\%) experienced at least one unit decrease in SPPB scores. These declines over a relatively short period are disturbing, which highlights the need for timely community nutritional and physical function assessment and appropriate strategies to address declines. The prevalence of malnutrition or at risk of malnutrition at both time points within this present study was more than double the estimated prevalence of malnutrition in the UK. It is estimated that more than 3 million older adults suffer from malnutrition, which accounts for more than $10 \%$ of the population aged 65 years and older [54, 55]. However, as seasonality is known to impact on eating behaviours and physical function, the season in which data were collected could have affected participants' nutrient intake and subsequent nutritional status, leading to the high proportion of malnourished/at risk of malnutrition observed among this sample [43]. Despite this, the prevalence of malnutrition or at risk of malnutrition in studies outside the UK reported considerably higher percentages than the current study [56,57]. For example, a study of 360 older adults aged 60 years and over in India found that $70 \%$ of the sample were malnourished or at risk of malnutrition [56].

The relationship between physical function and nutritional status in the present study confirms the findings of previous studies [58, 59]. A study of 457 randomly selected older Bangladeshis living in rural communities found that poorer nutritional status, increased age and co-morbidities, and being female were associated with functional limitations [57]. One possible explanation for this relationship could be the difficulty in shopping and preparing food, especially their traditional meals, due to physical limitations, which could eventually lead to inadequate dietary intake and malnutrition, which further exacerbates their physical function limitations $[43,59]$.

There was no significant relationship between sex and nutritional status in this present study. The role of women in society and their relative financial dependency partly accounts for the differences in nutritional status as reported by previous studies $[56,60]$. However, within this study, there was no difference in education and deprivation (IMD scores) between sexes, suggesting that females may have been more comparable to males with regards to resources and access to healthier foods, and hence could afford to cook and eat diets similar to their male counterparts. Also, it could be assumed that by virtue of western economic culture and the availability of supermarkets in the Birmingham area, females had fairly equal access to food as compared to traditional customs of some cultures where men eat first, and older women tend to give their share of their food to other family members, especially their grandchildren [59].

The strengths of this study include the use of the multiple-pass 24-hour recall approach on four-non-consecutive days (including a weekend day) compared to the use of a single 24-hour recall by previous studies which fails to account for day-to-day variation, or the FFQ which has been found to overestimate energy and nutrient intakes in older adults $[11,27,61]$. However, it is important to acknowledge the high possibility of under-reporting and recall bias in this study. Under-reporting contributes to a significant amount of error in dietary reporting and is even higher in overweight and obese populations, such as those participating in the present study [62]. Additionally, the number of days used in assessing diet in this present study was insufficient to capture some nutrients. Studies have reported a range of 3 to 9 days of 24-hour recalls to capture a true representation of energy and macronutrients, and a much wider range of 4 to 160 days of 24-hour recalls to capture a true representation of micronutrient intakes [63].

Furthermore, given the influence of seasonality and increasing age on dietary intake and nutritional status, the eight months' follow-up period within this present study may have been relatively short to assess the changes in these variables accurately. Hence, one must exercise caution in drawing any firm conclusions from these findings, as they can only provide an insight into the potential changes in dietary trends and nutritional status over time within this population. Future studies with more extended follow-up periods, which control for seasonality, are required to investigate the dietary trends and nutritional status within this population. Lastly, even though the maximum variation technique was used during sampling to ensure a more diverse sample, it was challenging to recruit South Asian females, especially females self-identifying as Bangladeshi. Thus, the findings are not generalizable to all ethnic minorities living in the UK. 
Implications for Research and Practice

Given the declines in nutritional status and physical function observed within a relatively short period, strategies for implementing a community-led programme around early nutritional and physical function assessments at community and faith/religious centres could help to identify and treat malnutrition and physical function limitations before further deterioration. The co-creation of such programmes with health care professionals and community/faith leaders may be effective in increasing accessibility and acceptability of these assessments, and also ensure that consistent health messages are delivered across communities. Interventions that are co-created and run at faith centres have been shown to increase access and improve health outcomes [64, 65]. These benefits can serve as a strong incentive for community-dwelling older adults to visit these meeting places to improve their social networks, which is equally essential for a healthier ageing trajectory.

As previously reported in this same sample, fear of gaining weight and engagement in unhealthy practices to lose weight were observed [43]. The practice of fasting, skipping meals, or drastically reducing portion sizes without proper adherence to diet quality are common practices, which may have contributed to the observed low nutrient intakes in this study. While future studies are recommended to explore this in detail, health professionals could change their advice and avoid generic messages such as "you are overweight/obese, so you need to lose weight," and instead deliver more individually tailored messages to achieve weight loss using healthier practices that do not negatively impact nutritional quality of one's diet.

Lastly, given the importance of supplementation and the low supplement intakes observed in this study, this population would benefit from a free supplementation programme $[66,67]$. To increase compliance, such a programme could be integrated into already existing community or faith group activities. Additionally, health professionals, specifically nutritionists and dieticians attending to older ethnic minorities, could include a mandatory dietary assessment and based on the results, prescribe free supplements if needed, in line with safer intake thresholds, to enhance acceptability and intake to improve nutrient status among this population. This practice could be complemented with appropriately tailored dietary education to ensure that these supplements do not replace a well-balanced diet.

\section{Conclusions}

The present findings indicate that community-dwelling, ethnically diverse older adults consume most micronutrients below the UK RNI over time. In a relatively short period of follow-up, there were significant declines in nutrient intakes (folate, vitamin B1, vitamin B6, magnesium and iron), nutritional status and physical function among this population. These declines, and the observed associations between nutritional status and physical function over time highlight the need for enhanced community programmes targeting early screening of nutritional status and physical function to ensure most older adults are assessed and treated accordingly. Additionally, the inclusion of dietary assessments, provision of free dietary supplements and culturally tailored dietary education by health professionals could improve nutritional intake among this population. Future studies with a longer follow-up period and larger sample size are recommended to confirm the findings of this study.

\section{Abbreviations}

WC= Waist Circumference; Cl: Confidence interval; SD: Standard Deviation; SD= Standard deviation; IMD= Index of Multiple Deprivation; MNA-SF= MiniNutritional Assessment-Short Form; SPPB= Short Physical Performance Battery HGS= Handgrip strength; BMI= Body Mass Index

\section{Declarations}

Ethics approval and consent to participate

The study received approval by the University of Birmingham Science, Technology, Engineering and Mathematics (STEM) research ethics committee (ERN_17_1364). All participants signed an informed consent before data collection commenced.

Consent for publication

Not applicable

Availability of data and materials

The datasets generated and analysed during the current study are part of a larger PANINI network data set containing unpublished data, hence are not currently available. The data will be made available after completion of the Innovative Training Network (ITN) project.

Competing interest

The authors declare no competing interest.

Funding

The European Commission funded this study as part of the Horizon 2020 Physical Activity and Nutritional INfluences In ageing (PANINI) Innovative Training Network, under which EAA is a Marie Curie Early Stage Researcher, and JLT and CAG were his doctoral supervisors (Grant number: 675003).

http://www.birmingham.ac.uk/panini

Author's contribution

Page $7 / 14$ 
EAA designed and carried out data collection, data analysis/interpretation and wrote the first draft of the manuscript. JLT conceptualised and obtained funding for the project, provided oversight on data collection, analyses and interpretation throughout the project, and revised all versions of the manuscript. CAG contributed to supervision and interpretation of the data and editing of the manuscript. All authors read and approved the final version of the manuscript.

Acknowledgements

The authors would like to express their profound gratitude to the study participants, and community/faith leaders and interpreters who supported recruitment and data collection. We would like to specifically thank the West Bromwich African Caribbean Resource Centre, Halesowen Asian Elderly Association, Ward End Asian Elders, and all the faith centres that supported this study.

\section{References}

1. World population Ageing [https://www.un.org/en/development/desa/population/publications/pdf/ageing/WPA2015_Report.pdf]

2. Living longer: how our population is changing and why it matters

[https://www.ons.gov.uk/peoplepopulationandcommunity/birthsdeathsandmarriages/ageing/articles/livinglongerhowourpopulationischangingandwhyitn 08-13]

3. National population projections: 2016-based-Office for National Statistics

[https://www.ons.gov.uk/peoplepopulationandcommunity/populationandmigration/populationprojections/bulletins/nationalpopulationprojections/2016t

4. Lievesley N: The ageing of the ethnic minority populations of England and Wales: findings from the 2011 census. CPA, UK 2013.

5. Briefing: Health and care of older people in England [https://www.ageuk.org.uk/Documents/EN-GB/Forprofessionals/Research/The_Health_and_Care_of_Older_People_in_England_2016.pdf?dtrk=true]

6. Vertovec S: Super-diversity and its implications. Ethnic and racial studies 2007, 30(6):1024-1054.

7. Households below average income: An analysis of the income distribution 1994/95 to 2013/14 [https://assets.publishing.service.gov.uk/government/uploads/system/uploads/attachment_data/file/437246/households-below-average-income-199495-to-2013-14.pdf]

8. Evandrou M, Falkingham J, Feng Z, Vlachantoni A: Ethnic inequalities in limiting health and self-reported health in later life revisited. $J$ Epidemiol Community Health 2016, 70(7):653-662.

9. Nazroo JY: The health of Britain's ethnic minorities: findings from a national survey. London: PSI; 1997.

10. Health Survey for England 2004. The health of minority ethnic groups [https://lemosandcrane.co.uk/resources/National\%20Statistics\%20\%20Health\%20Survey\%20for\%20England\%202004.pdf]

11. Castaneda-Gameros D, Redwood S, Thompson JL: Nutrient Intake and Factors Influencing Eating Behaviors in Older Migrant Women Living in the United Kingdom. Ecology of food and nutrition 2018, 57(1):50-68.

12. Gatineau M, Mathrani S: Ethnicity and obesity in the UK. Perspectives in public health 2011, 131(4):159.

13. Gilbert PA, Khokhar S: Changing dietary habits of ethnic groups in Europe and implications for health. Nutrition Reviews 2008, 66(4):203-215.

14. Emadian A, England CY, Thompson JL: Dietary intake and factors influencing eating behaviours in overweight and obese South Asian men living in the UK: mixed method study. BMJ open 2017, 7(7):e016919.

15. Garduno-Diaz S, Khokhar S: Eating habits and nutrient intake of migrant South Asians in the UK. Public health 2014, 128(11):1043-1046.

16. Gómez JF, Curcio C-L, Alvarado B, Zunzunegui MV, Guralnik J: Validity and reliability of the Short Physical Performance Battery (SPPB): a pilot study on mobility in the Colombian Andes. Colombia Medica 2013, 44(3):165-171.

17. Guralnik JM, Simonsick EM, Ferrucci L, Glynn RJ, Berkman LF, Blazer DG, Scherr PA, Wallace RB: A short physical performance battery assessing lower extremity function: association with self-reported disability and prediction of mortality and nursing home admission. Journal of gerontology 1994 , 49(2):M85-M94.

18. Landi F, Calvani R, Tosato M, Martone AM, Bernabei R, Onder G, Marzetti E: Impact of physical function impairment and multimorbidity on mortality among community-living older persons with sarcopaenia: results from the ilSIRENTE prospective cohort study. BMJ open 2016, 6(7):e008281.

19. Louie GH, Ward MM: Socioeconomic and ethnic differences in disease burden and disparities in physical function in older adults. American journal of public health 2011, 101(7):1322-1329.

20. Williams ED, Tillin T, Whincup P, Forouhi NG, Chaturvedi N: Ethnic differences in disability prevalence and their determinants studied over a 20-year period: a cohort study. PLoS One 2012, 7(9):e45602.

21. Kimura Y, Wada T, Ishine M, Ishimoto Y, Kasahara Y, Konno A, Nakatsuka M, Sakamoto R, Okumiya K, Fujisawa M: Food diversity is closely associated with activities of daily living, depression, and quality of life in community-dwelling elderly people. Journal of the American Geriatrics Society 2009 , 57(5):922-924.

22. Kuczmarski MF, Weddle DO, Jones EM: Maintaining functionality in later years: a review of nutrition and physical activity interventions in postmenopausal women. Journal of Nutrition for the Elderly 2010, 29(3):259-292.

23. Population and census [https://www.birmingham.gov.uk/info/20057/about_birmingham/1294/population_and_census/2]

24. 2016 Population Based Projections [https://www.birmingham.gov.uk/downloads/file/4609/2016_population_basedprojections]

25. Teddlie C, Yu F: Mixed methods sampling: A typology with examples. Journal of Mixed Methods Research 2007, 1(1):77-100.

26. English indices of deprivation [https://www.gov.uk/government/statistics/english-indices-of-deprivation-2015] 
27. Adamson A, Collerton J, Davies K, Foster E, Jagger C, Stamp E, Mathers J, Kirkwood T: Nutrition in advanced age: dietary assessment in the Newcastle 85+ study. European Journal of Clinical Nutrition 2009, 63(S1):S6.

28. Cheyette C, Balolia Y: Carbs \& Cals: A Visual Guide to Carbohydrate Counting \& Calorie Counting for People with Diabetes: Chello; 2010.

29. Department of Health: Dietary reference values for food energy and nutrients for the United Kingdom In: Report on Health and Social Subjects 41 Report of the Panel on Dietary Reference Values of the Committee on Medical Aspects of Food Policy edn. London, UK: HMSO; 1991.

30. Vellas B, Guigoz Y, Garry PJ, Nourhashemi F, Bennahum D, Lauque S, Albarede J-L: The Mini Nutritional Assessment (MNA) and its use in grading the nutritional state of elderly patients. Nutrition 1999, 15(2):116-122.

31. Cuervo M, García A, Ansorena D, Sanchez-Villegas A, Martínez-González M, Astiasarán I, Martínez JA: Nutritional assessment interpretation on 22007 Spanish community-dwelling elders through the Mini Nutritional Assessment test. Public health nutrition 2009, 12(1):82-90.

32. Rubenstein LZ, Harker JO, Salvà A, Guigoz Y, Vellas B: Screening for undernutrition in geriatric practice: developing the short-form mini-nutritional assessment (MNA-SF). The Journals of Gerontology Series A: Biological Sciences and Medical Sciences 2001, 56(6):M366-M372.

33. Whittaker AC, Asamane EA, Aunger JA, Bondarev D, Cabbia A, Doody PD, Gensous N, ladarola B, Ramsey KA, Rodrigues B: Physical Activity and Nutrition INfluences in Ageing: Current Findings from the PANINI Project. Advances in Geriatric Medicine and Research 2019, 1(1).

34. Guralnik JM, Ferrucci L, Pieper CF, Leveille SG, Markides KS, Ostir GV, Studenski S, Berkman LF, Wallace RB: Lower extremity function and subsequent disability: consistency across studies, predictive models, and value of gait speed alone compared with the short physical performance battery. The Journals of Gerontology Series A: Biological Sciences and Medical Sciences 2000, 55(4):M221-M231.

35. National Health and Nutrition Examination Survey Questionnaire (Muscle strength, Procedures Manual) [https://www.cdc.gov/nchs/data/nhanes/nhanes_11_12/muscle_strength_proc_manual.pdf]

36. Reijnierse EM, de Jong N, Trappenburg MC, Blauw GJ, Butler-Browne G, Gapeyeva H, Hogrel JY, McPhee JS, Narici MV, Sipilä S: Assessment of maximal handgrip strength: how many attempts are needed? Journal of cachexia, sarcopenia and muscle 2017, 8(3):466-474.

37. El-Sais WM, Mohammad WS: Influence of different testing postures on hand grip strength. European Scientific Journal 2014, 10(36).

38. Willett WC, Howe GR, Kushi LH: Adjustment for total energy intake in epidemiologic studies. The American Journal of Clinical Nutrition 1997, 65(4):1220S$1228 \mathrm{~S}$.

39. Roberts HC, Denison HJ, Martin HJ, Patel HP, Syddall H, Cooper C, Sayer AA: A review of the measurement of grip strength in clinical and epidemiological studies: towards a standardised approach. Age and ageing 2011, 40(4):423-429.

40. Ethnicity and National Identity in England and Wales 2011 [http://webarchive.nationalarchives.gov.uk/20160105160709/http://www.ons.gov.uk/ons/dcp171776_290558.pdf ]

41. Anderson A, Lean M: Healthy changes? Observations on a decade of dietary change in a sample of Glaswegian South Asian migrant women. Journal of Human Nutrition and Dietetics 1995, 8(2):129-136.

42. Zhang H, Hsu-Hage BH, Wahlqvist ML: Longitudinal changes in nutrient intakes in the Melbourne Chinese Cohort Study. Public Health Nutrition 2002, 5(3):433-439.

43. Asamane EA, Greig CA, Aunger JA, Thompson JL: Perceptions and Factors Influencing Eating Behaviours and Physical Function in Community-Dwelling Ethnically Diverse Older Adults: A Longitudinal Qualitative Study. Nutrients 2019, 11(6):1224.

44. Caireen Roberts TS, Natalie Maplethorpe, Lorna Cox, Sarah, Meadows SN, Polly Page, and Gillian Swan: National Diet and Nutrition Survey. Results from Years 7 and 8 (combined) of the Rolling Programme (2014/2015 to 2015/2016). In.: Department of Health and Food Standards Agency; 2018.

45. Mendonça N, Hill TR, Granic A, Davies K, Collerton J, Mathers JC, Siervo M, Wrieden WL, Seal CJ, Kirkwood TB: Macronutrient intake and food sources in the very old: analysis of the Newcastle 85+ Study. British Journal of Nutrition 2016, 115(12):2170-2180.

46. Vyas A, Greenhalgh A, Cade J, Sanghera B, Riste L, Sharma S, Cruickshank K: Nutrient intakes of an adult Pakistani, European and African-Caribbean community in inner city Britain. Journal of Human Nutrition and Dietetics 2003, 16(5):327-337.

47. Anderson A, Bush H, Lean M, Bradby H, Williams R, Lea E: Evolution of atherogenic diets in South Asian and Italian women after migration to a higher risk region. Journal of Human Nutrition and Dietetics 2005, 18(1):33-43.

48. Johnson CS, Garcia AC: Dietary and activity profiles of selected immigrant older adults in Canada. Journal of Nutrition for the Elderly 2003, 23(1):23-39.

49. Older People Living in the Community-Nutritional Needs, Barriers and Interventions: A Literature Review

[http://www.scotland.gov.uk/Publications/2009/12/07101949/1]

50. Stratton RJ, Elia M: Deprivation linked to malnutrition risk and mortality in hospital. British Journal of Nutrition 2006, 96(5):870-876.

51. Aspell N, Laird E, Healy M, Shannon T, Lawlor B, O'Sullivan M: The Prevalence and Determinants of Vitamin D Status in Community-Dwelling Older Adults: Results from the English Longitudinal Study of Ageing (ELSA). Nutrients 2019, 11(6):1253.

52. Beaudart C, Buckinx F, Rabenda V, Gillain S, Cavalier E, Slomian J, Petermans J, Reginster J-Y, Bruyère O: The effects of vitamin D on skeletal muscle strength, muscle mass, and muscle power: a systematic review and meta-analysis of randomized controlled trials. The Journal of Clinical Endocrinology \& Metabolism 2014, 99(11):4336-4345.

53. Bischoff-Ferrari HA, Willett WC, Wong JB, Stuck AE, Staehelin HB, Orav EJ, Thoma A, Kiel DP, Henschkowski J: Prevention of nonvertebral fractures with oral vitamin D and dose dependency: a meta-analysis of randomized controlled trials. Archives of Internal Medicine 2009, 169(6):551-561.

54. Malnutrition among Older People in the Community: Policy Recommendations for Change [https://www.bapen.org.uk/pdfs/malnut_in_the_community.pdf] 
55. Elia M, Stratton RJ: Geographical inequalities in nutrient status and risk of malnutrition among English people aged $65 \mathrm{y}$ and older. Nutrition 2005, 21(1112):1100-1106.

56. Agarwalla R, Saikia AM, Baruah R: Assessment of the nutritional status of the elderly and its correlates. Journal of Family \& Community Medicine 2015, 22(1):39.

57. Ferdous T, Cederholm T, Razzaque A, Wahlin $\AA$, Nahar Kabir Z: Nutritional status and self-reported and performance-based evaluation of physical function of elderly persons in rural Bangladesh. Scandinavian Journal of Public Health 2009, 37(5):518-524.

58. Danielewicz AL, Barbosa AR, Del Duca GF: Nutritional status, physical performance and functional capacity in an elderly population in southem Brazil. Revista da Associação Médica Brasileira 2014, 60(3):242-248.

59. Kikafunda JK, Lukwago FB: Nutritional status and functional ability of the elderly aged 60 to 90 years in the Mpigi district of central Uganda. Nutrition 2005, 21(1):59-66.

60. Donini LM, Scardella P, Piombo L, Neri B, Asprino R, Proietti A, Carcaterra S, Cava E, Cataldi S, Cucinotta D: Malnutrition in elderly: social and economic determinants. The journal of Nutrition, Health \& Aging 2013, 17(1):9-15.

61. Earland J, Campbell J, Srivastava A: Dietary habits and health status of African-Caribbean adults. Journal of human nutrition and dietetics 2010 , 23(3):264-271

62. Rennie KL, Coward A, Jebb SA: Estimating under-reporting of energy intake in dietary surveys using an individualised method. British Journal of Nutrition 2007, 97(6):1169-1176.

63. Tokudome Y, Imaeda N, Nagaya T, Ikeda M, Fujiwara N, Sato J, Kuriki K, Kikuchi S, Maki S, Tokudome S: Daily, weekly, seasonal, within-and betweenindividual variation in nutrient intake according to four season consecutive 7 day weighed diet records in Japanese female dietitians. Journal of epidemiology 2002, 12(2):85-92.

64. DeHaven MJ, Hunter IB, Wilder L, Walton JW, Berry J: Health programs in faith-based organizations: are they effective? American Journal of Public Health 2004, 94(6):1030-1036.

65. Sattin RW, Williams LB, Dias J, Garvin JT, Marion L, Joshua TV, Kriska A, Kramer MK, Narayan KV: Community trial of a faith-based lifestyle intervention to prevent diabetes among African-Americans. Journal of community health 2016, 41(1):87-96.

66. Talwar SA, Aloia JF, Pollack S, Yeh JK: Dose response to vitamin D supplementation among postmenopausal African American women. The American journal of clinical nutrition 2007, 86(6):1657-1662.

67. Blumberg J, Frei B, Fulgoni III V, Weaver C, Zeisel S: Contribution of dietary supplements to nutritional adequacy in race/ethnic population subgroups in the United States. Nutrients 2017, 9(12):1295.

68. Bauer J, Biolo G, Cederholm T, Cesari M, Cruz-Jentoft AJ, Morley JE, Phillips S, Sieber C, Stehle P, Teta D: Evidence-based recommendations for optimal dietary protein intake in older people: a position paper from the PROT-AGE Study Group. Journal of the american Medical Directors association 2013, 14(8):542-559

\section{Tables}

Table 1: Socio-Demographic Characteristics and Other Health-Related Information at Baseline and 8-Months' Follow-Up. 


\begin{tabular}{|c|c|c|c|}
\hline \multicolumn{2}{|l|}{ Variables } & Baseline $(n=100)$ & Follow-up $(\mathrm{n}=81)$ \\
\hline \multicolumn{2}{|l|}{ Age, years Mean (SD) } & $70.8(8.1)$ & $70.7(8.2)$ \\
\hline \multicolumn{2}{|l|}{ Male N (\%) } & $59(59.0)$ & $50(62.0)$ \\
\hline \multirow[t]{6}{*}{ Ethnicity N (\%) } & Pakistani & $23(23.0)$ & $15(18.5)$ \\
\hline & Indian & $7(7.0)$ & $5(6.2)$ \\
\hline & Bangladeshi & $4(4.0)$ & $2(2.5)$ \\
\hline & Caribbean & $41(41.0)$ & $38(46.9)$ \\
\hline & African & $19(19.0)$ & 15 (18.5) \\
\hline & Others & $6(6.0)$ & $6(7.4)$ \\
\hline \multirow[t]{4}{*}{ Marital status N (\%) } & Single & $4(4.0)$ & $3(3.7)$ \\
\hline & Married & $66(66.0)$ & $55(67.9)$ \\
\hline & Divorced & $14(14.0)$ & $12(14.8)$ \\
\hline & Widowed & $16(16.0)$ & $11(13.6)$ \\
\hline \multirow[t]{5}{*}{ Faith/Religion N (\%) } & No religion & $1(1.0)$ & $1(1.2)$ \\
\hline & Hindu & $2(2.0)$ & $2(2.5)$ \\
\hline & Sikh & $7(7.0)$ & $4(5.0)$ \\
\hline & Muslim & $34(34.0)$ & $24(29.6)$ \\
\hline & Christian & $56(56.0)$ & $50(61.7)$ \\
\hline \multirow[t]{4}{*}{ Education N (\%) } & No education & $16(16.0)$ & $11(13.6)$ \\
\hline & Primary & $16(16.0)$ & $14(17.3)$ \\
\hline & Secondary & $21(21.0)$ & $15(18.5)$ \\
\hline & College/University & $47(47.0)$ & $41(50.6)$ \\
\hline \multirow[t]{4}{*}{ Self-rated health N (\%) } & Excellent & $18(18.0)$ & $16(19.7)$ \\
\hline & Good & $55(55.0)$ & $45(55.6)$ \\
\hline & Fair & $16(16.0)$ & $11(13.6)$ \\
\hline & Poor & $11(11.0)$ & $9(11.1)$ \\
\hline \multicolumn{2}{|c|}{ No. of diseases Mean (SD) } & $2.0(1.4)$ & $2.1(1.4)$ \\
\hline \multirow[t]{4}{*}{ IMD Decile N (\%) } & 1 (Most deprived) & $33(33.0)$ & $29(35.8)$ \\
\hline & 2 & $19(19.0)$ & $19(23.4)$ \\
\hline & 3 & $22(22.0)$ & $11(13.6)$ \\
\hline & 4 (least deprived) & $26(26.0)$ & $22(27.2)$ \\
\hline \multirow[t]{3}{*}{ BMI categories* N (\%) } & Normal & $7(7.0)$ & $9(11.1)$ \\
\hline & Overweight & $31(31.0)$ & $21(25.9)$ \\
\hline & Obese & $62(62.0)$ & $51(63.0)$ \\
\hline \multirow{3}{*}{$\begin{array}{l}\text { aNutritional status by } \\
\text { MNA-SF } \mathrm{N}(\%)^{* *}\end{array}$} & Malnourished & $2(2.0)$ & $1(1.2)$ \\
\hline & At- risk of malnutrition & $22(22.0)$ & $29(35.8)$ \\
\hline & Normal & $76(76.0)$ & $51(63.0)$ \\
\hline \multicolumn{2}{|c|}{ asPPB score Median (IQR) ** } & $11.1(4.0)$ & $10.0(4.0)$ \\
\hline \multicolumn{2}{|l|}{ HGS Mean (SD) } & $27.6(9.8)$ & $26.5(9.5)$ \\
\hline \multicolumn{2}{|l|}{ WC Mean (SD) } & $100.3(10.6)$ & $100.8(10.6)$ \\
\hline
\end{tabular}

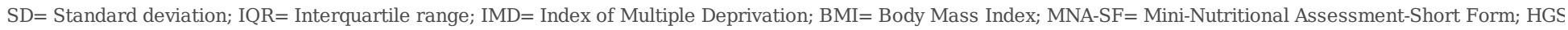

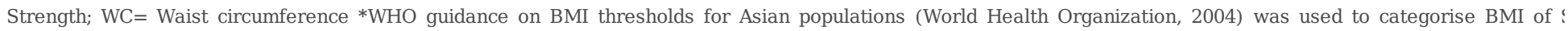



Table 2: Macronutrient and Energy Intake of Community-dwelling, Ethnically Diverse Older Adults at Baseline and Follow-up (N=81) 
Baseline

Follow-up



$\Gamma E=$ Percentage of Total Energy; RNI = reference nutrient intake SD = Standard deviation; IQR =interquartile Range; g= gram $* \mathrm{P}$ values showing significant difference in nutrient intake for the two time points; ** Department of Health (1991) and Scientific Advisory Committee on Nutrition (2012).

Table 3: Energy and Macronutrient Contribution to Energy by Ethnicity Over Time

\begin{tabular}{|c|c|c|c|c|c|c|c|c|}
\hline & \multicolumn{4}{|c|}{ Baseline $(n=100)$} & \multicolumn{4}{|c|}{ Follow-up ( $n=81)$} \\
\hline & $\begin{array}{l}\text { South Asian ( } n= \\
\text { 34) }\end{array}$ & $\begin{array}{l}\text { African/ } \\
\text { Caribbean ( } \mathrm{n}= \\
60)\end{array}$ & $\begin{array}{l}\text { Others }(n= \\
6)\end{array}$ & $\begin{array}{l}\text { P- } \\
\text { value }\end{array}$ & $\begin{array}{l}\text { South Asian ( } \mathrm{n}= \\
\text { 22) }\end{array}$ & $\begin{array}{l}\text { African/ Caribbean ( } \mathrm{n}= \\
\text { 53) }\end{array}$ & Others $(n=6)$ & P-value \\
\hline cal/day & 1900.5 & 1615.8 & 1873.3 & 0.003 & 1969.8 & 1470.0 & 1641.5 & 0.003 \\
\hline bs & 48.6 & 49.0 & 43.9 & 0.625 & 48.3 & 55.4 & 53.0 & 0.141 \\
\hline ars & 12.1 & 15.1 & 17.4 & 0.119 & 14.9 & 17.4 & 20.5 & 0.056 \\
\hline tein & 16.4 & 17.7 & 13.8 & 0.013 & 15.3 & 16.4 & 13.8 & 0.444 \\
\hline 3 & 37.6 & 32.4 & 42.8 & 0.019 & 36.6 & 30.1 & 31.3 & 0.048 \\
\hline urated fats & 10.0 & 10.8 & 13.0 & 0.687 & 12.0 & 10.7 & 12.1 & 0.329 \\
\hline aturated & 11.1 & 11.3 & 13.4 & 0.385 & 10.8 & 10.4 & 11.3 & 0.768 \\
\hline runsaturated & 7.2 & 4.9 & 7.0 & $<0.001$ & 8.1 & 4.3 & 5.6 & $<0.001$ \\
\hline ake g/day & 16.0 & 15.0 & 20.6 & 0.256 & 17.2 & 15.9 & 20.3 & 0.285 \\
\hline
\end{tabular}

Table 4: Hierarchical Multiple Regression Predicting SPPB and HGS Scores (N=100) 
SPPB

HGS (kg)

\begin{tabular}{|c|c|c|c|c|c|c|c|c|}
\hline Predictors & B $(95 \% \mathrm{CI})$ & $\mathrm{SE}$ & p-value & $R^{2}$ change & B $(95 \% \mathrm{CI})$ & SE & p-value & $R^{2}$ change \\
\hline (Constant) & $24.52(16.40,32.64)$ & 4.09 & $<0.001$ & & $69.48(42.33,96.63)$ & 13.66 & $<0.001$ & \\
\hline \multicolumn{9}{|l|}{ Sociodemographic variables } \\
\hline Male vs female & $-0.05(-1.11,1.01)$ & 0.53 & 0.930 & \multirow[t]{6}{*}{0.216} & $-3.02(-6.56,0.52)$ & 1.78 & 0.093 & \multirow[t]{6}{*}{0.342} \\
\hline Age & $-0.09(-0.15,-0.03)$ & 0.03 & $<0.001$ & & $-0.45(-0.65,-0.25)$ & 0.1 & $<0.001$ & \\
\hline Married vs not married & $-1.34(-2.45,-0.24)$ & 0.55 & 0.020 & & $-0.53(-1.30,0.24)$ & 0.39 & 0.177 & \\
\hline IMD & $0.14(-0.09,0.37)$ & 0.12 & 0.240 & & $-1.41(-2.66,-0.15)$ & 0.63 & 0.028 & \\
\hline No education vs Education & $-1.23(-2.64,0.18)$ & 0.71 & 0.090 & & $1.17(-3.54,5.88)$ & 2.37 & 0.623 & \\
\hline Number of diseases & $-0.26(-0.64,0.11)$ & 0.19 & 0.170 & & $-2.87(-6.56,0.82)$ & 1.85 & 0.125 & \\
\hline Nutritional status (by MNA-SF) & $0.39(0.10,0.67)$ & 0.14 & 0.010 & 0.091 & $0.16(-0.78,1.10)$ & 0.47 & 0.732 & 0.009 \\
\hline WC & $-0.15(-0.22,-0.09)$ & 0.03 & $<0.001$ & \multirow[t]{2}{*}{0.152} & $-0.05(-0.52,0.42)$ & 0.24 & 0.834 & \multirow[t]{2}{*}{0.010} \\
\hline BMI & $0.12(-0.02,0.26)$ & 0.07 & 0.090 & & $-0.06(-0.28,0.16)$ & 0.11 & 0.579 & \\
\hline \multicolumn{9}{|l|}{ Nutrient intakes } \\
\hline Fibre & $0.08(0.02,0.15)$ & 0.03 & 0.010 & \multirow[t]{3}{*}{0.075} & $0.28(0.07,0.50)$ & 0.11 & 0.011 & \multirow[t]{3}{*}{0.061} \\
\hline Vitamin D & $-0.04(-0.12,0.04)$ & 0.04 & 0.340 & & $-0.19(-0.45,0.08)$ & 0.13 & 0.164 & \\
\hline Vitamin B6 & $1.33(0.35,2.32)$ & 0.49 & 0.010 & & $1.33(-1.95,4.62)$ & 1.65 & 0.421 & \\
\hline Total $R^{2}$ & & & & 0.534 & & & & 0.423 \\
\hline
\end{tabular}

te $\mathrm{N}=100 ; \mathrm{WC}=$ Waist Circumference; IMD= Index of Multiple Deprivation; $\mathrm{BMI}=$ Body Mass Index; $\mathrm{MNA}-\mathrm{SF}=\mathrm{Mini}-\mathrm{Nutritional}$ Assessment

Table 5: Hierarchical Linear Regression Showing Predictors of Nutritional Status (N=100).

\begin{tabular}{lcccc}
\hline Predictors & B (95\%CI) & SE & P-value & $R^{2}$ change \\
\hline (Constant) & $8.50(1.57,15.44)$ & 3.47 & 0.017 & \\
\hline Sociodemographic variables & & & & \\
\hline Male vs female & $0.17(-0.61,0.96)$ & 0.39 & 0.664 & 0.107 \\
\hline Age & $0.02(-0.03,0.07)$ & 0.02 & 0.379 & \\
\hline Married vs not married & $-0.34(-1.16,0.49)$ & 0.41 & 0.420 \\
\hline IMD & $-0.14(-0.31,0.03)$ & 0.09 & 0.112 & \\
\hline No education vs Education & $0.27(-0.78,1.33)$ & 0.53 & 0.607 & \\
\hline Number of diseases & $-0.24(-0.52,0.03)$ & 0.14 & 0.085 & \\
\hline WC & $-0.02(-0.04,0.07)$ & 0.03 & 0.535 & 0.017 \\
\hline BMI & $0.01(-0.11,0.10)$ & 0.05 & 0.953 & \\
\hline Physical function & & & & \\
\hline SPPB & $0.25(0.08,0.42)$ & 0.09 & 0.004 & 0.096 \\
\hline HGS & $-0.03(-0.08,0.03)$ & 0.03 & 0.253 & \\
\hline Nutrient intakes & & & & \\
\hline Fibre & $0.02(-0.03,0.06)$ & 0.02 & 0.530 & 0.036 \\
\hline Vitamin D & $-0.05(-0.11,0.01)$ & 0.03 & 0.092 & \\
\hline Vitamin B6 & $-0.15(-0.90,0.59)$ & 0.37 & 0.687 & \\
\hline Total $R^{2}$ & & & & 0.256 \\
\hline
\end{tabular}

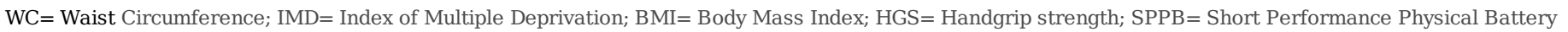

Table 6: Multinomial regression of factors predicting nutritional status membership at follow-up $(n=81)$ 
Remained At Risk/Malnourished Changed to At-Risk/Malnourished Changed to Normal

\begin{tabular}{|c|c|c|c|c|c|c|c|c|c|}
\hline & $\mathrm{D}$ & $\mathrm{CF}$ & & 8 & & & 8 & & \\
\hline & & & & & & & & & \\
\hline Intercept & -0.14 & 11.2 & & 1.39 & 7.29 & & -25.66 & 15.25 & \\
\hline BMI & 0.19 & 0.2 & $1.21(0.81-1.80)$ & 0.26 & 0.12 & $1.29(1.01-1.65)^{*}$ & 0.29 & 0.31 & $1.34(0.72-2.48)$ \\
\hline HGS & -0.08 & 0.1 & $0.92(0.75-1.13)$ & -0.16 & 0.07 & $0.85(0.74-0.98)$ & -0.16 & 0.13 & $0.85(0.66-1.11)^{*}$ \\
\hline WC & -0.12 & 0.1 & $0.89(0.73-1.08)$ & 0.09 & 0.06 & $1.10(0.97-1.24)^{*}$ & 0.39 & 0.18 & $1.48(1.04-2.10)$ \\
\hline Age & 0.06 & 0.09 & $1.07(0.90-1.27)$ & 0.12 & 0.06 & $1.13(1.00-1.28)$ & 0.36 & 0.14 & $1.43(1.09-1.87)$ \\
\hline IMD & 0.21 & 0.46 & $1.23(0.50-3.05)$ & 0.40 & 0.19 & $1.49(1.03-2.16)^{*}$ & 1 & 0.38 & $2.71(1.30-5.68)^{*}$ \\
\hline SPPB & -0.26 & 0.32 & $0.77(0.41-1.45)$ & -0.49 & 0.22 & $0.61(0.40-0.94)^{*}$ & -0.85 & 0.45 & $0.43(0.18-1.03)$ \\
\hline Fibre & -0.28 & 0.15 & $0.75(0.56-1.02)$ & -0.1 & 0.06 & $0.91(0.81-1.02)$ & -0.07 & 0.11 & $0.93(0.75-1.15)$ \\
\hline Vitamin D & 0.16 & 0.13 & $1.18(0.92-1.51)$ & -0.05 & 0.1 & $0.95(0.78-1.16)$ & 0.12 & 0.18 & $1.13(0.79-1.60)$ \\
\hline Vitamin B6 & 1.17 & 1.53 & $3.23(0.16-64.96)$ & 0.05 & 0.78 & $1.05(0.23-4.79)$ & 0.11 & 1.44 & $1.12(0.07-18.7)$ \\
\hline Male & 3.07 & 1.9 & $21.56(0.52-892.87)$ & 0.5 & 0.8 & $1.64(0.34-7.90)$ & -1.53 & 1.86 & $0.22(0.01-8.31)$ \\
\hline Female & 1 & & & 1 & & & 1 & & \\
\hline Married & 0.2 & 1.41 & $1.22(0.08-19.22)$ & 0.93 & 0.93 & $2.54(0.41-15.67)$ & 1.76 & 2.08 & $0.25(0.10-3.43)$ \\
\hline No married & 1 & & & 1 & & & 1 & & \\
\hline Educated & 2.55 & 1.9 & $12.85(0.31-527.7)$ & 1.20 & 1.07 & $3.32(0.41-26.83)$ & -16.41 & 0 & $0.743(0.07-0.09)$ \\
\hline No education & 1 & & & 1 & & & 1 & & \\
\hline Number diseases $\leq 2$ & -0.54 & 1.81 & $0.59(0.02-20.21)$ & -1.28 & 0.93 & $0.28(0.05-1.71)$ & -2.18 & 1.9 & $0.25(0.03-4.69)$ \\
\hline Number diseases $>2$ & 1 & & & 1 & & & 1 & & \\
\hline
\end{tabular}

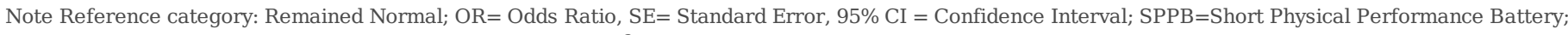
$\mathrm{IMD}=$ Index of Multiple Deprivation; $\mathrm{BMI}=$ Body Mass Index; $\mathrm{R}^{2}=0.63$ (Nagelkerke) $* * \mathrm{P}$ value $<0.01 * \mathrm{P}$ value $<0.05$

\section{Figures}

\section{Baseline and Follow-up nutrient intakes by percentage of RNI}

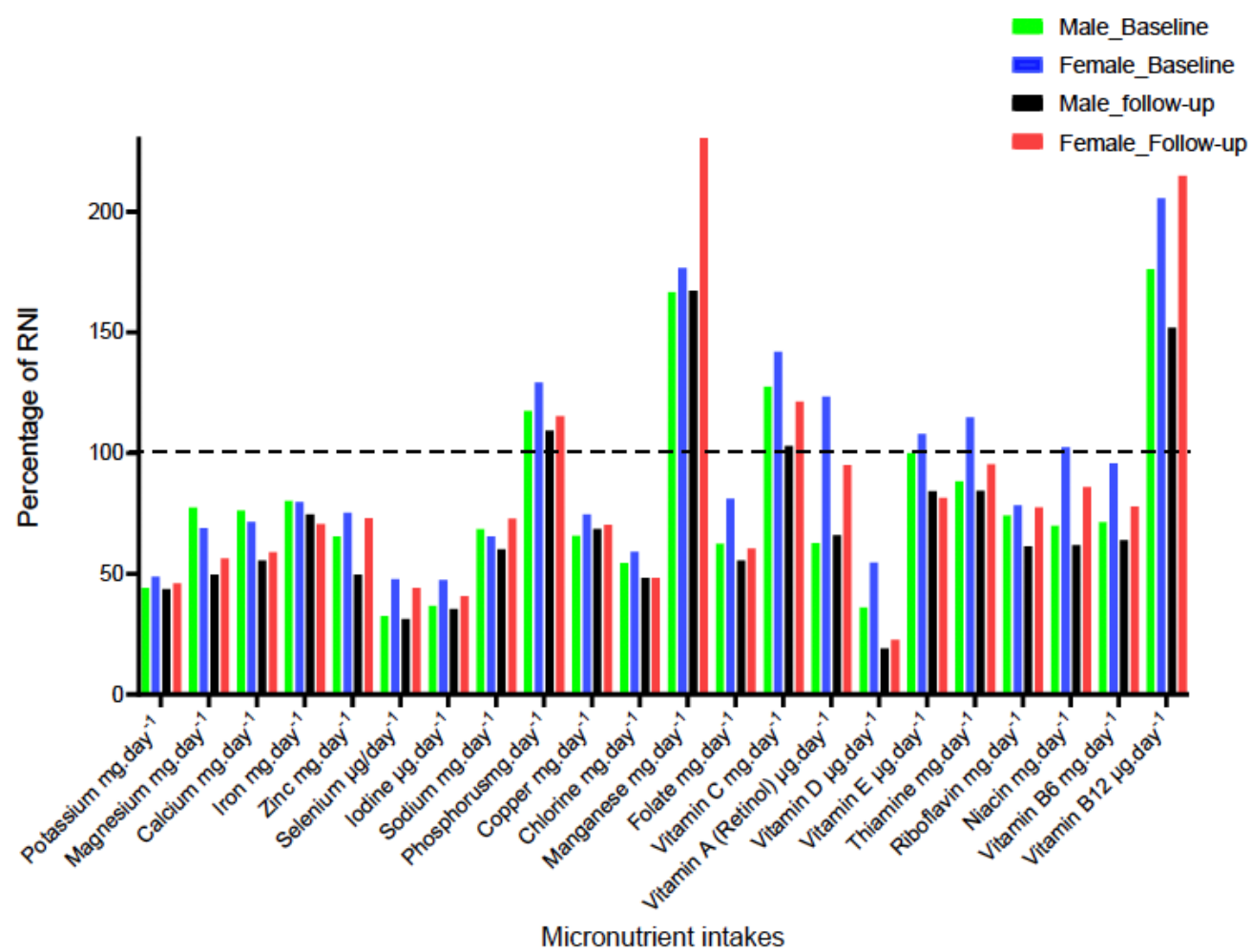

Figure 1

Percentage micronutrient intakes by UK RNI at baseline follow-up

\section{Supplementary Files}

This is a list of supplementary files associated with this preprint. Click to download.

- AdditionalFiles.docx 